\title{
Quilombos de Juazeiro: enfrentamentos e perspectivas a partir de uma abordagem fotoetnográfica $^{1}$
}

\author{
Márcia Guena Santos ${ }^{2}$
}

\section{Resumo}

Este artigo tem como objetivo traçar um perfil do processo incipiente de certificação de oito comunidades negras rurais quilombolas de Juazeiro (BA), de acordo com os parâmetros estabelecidos pela legislação em vigor, a partir de um conjunto de discussões e resultados obtidos na pesquisa "Perfil Fotoetonográfico das Populações Quilombolas do Submédio São Francisco: identidades em movimento". Tendo como principal referencial metodológico a fotoetnografia, esta pesquisa tem desenvolvido um banco de dados virtual, utilizando também outras linguagens da comunicação como vídeos e entrevistas gravadas, sobre essas comunidades tradicionais, com resultados concretos sobre oito delas, os quais têm mostrado a ausência de políticas públicas e de processos concretos que levem à certificação desses territórios, muitos dos quais tem uma história de ocupação quilombola de mais de 200 anos, com a preservação de traços importantes da cultura afrodescendente.

Palavras chave: Quilombos; Juazeiro; certificação quilombola;fotoetnografia.

\begin{abstract}
This article aims to draw a profile of the incipient process of accreditation seven Maroons rural black communities in Juazeiro ( BA ), according to the parameters established by legislation, from a set of discussions and research results in the "Report this profile Photoetonography Populations Quilombolas the submedium San Francisco: identities in motion". As the main methodological reference Photoethnography, this research has developed a virtual database using also other languages of communication as videos and interviews recorded on these traditional communities, with concrete results about seven of them, which have shown the absence of policies public in those communities and specific processes that lead to certification of these territories, many of which have a history of maroon occupancy of more than 200 years, with the preservation of important traits of African descent culture.
\end{abstract}

Keywords: Quilombos; Juazeiro; maroon certification; Photoethnography.

\section{Resumen}

Este artículo tiene como objetivo trazarun perfil del incipiente proceso de acreditaciónde sietecomunidadescimarrones negras ruralesen Juazeiro (BA ) , de

\footnotetext{
${ }^{1}$ Trabalho apresentado no III Encontro de Comunicação do Vale do São Francisco (ECOVALE), no eixo de Fotografia, Música, Cinema e Vídeo.

${ }^{2}$ Professora do curso de Comunicacional Social - Jornalismo em Multimeios da Universidade do Estado da Bahia (UNEB); Doutora em História pela Universidade Complutense de Madrid; Mestre em Integração na América Latina pela Universidade de São Paulo (USP); Jornalista pela Universidade de São Paulo.
} 
acuerdoconlosparámetrosestablecidos por lalegislación, a partir de una serie de debates y resultados de investigación "Perfil Fotoetonográficode poblaciones quilombolas em elsubmedium San Francisco: identidades enmovimiento" . Como principal referencia metodológico utilizamos La photoethnography. Esta investigación ha desarrollado una base de datosvirtual utilizando tambiénotroslenguajes de lacomunicación como vídeos y entrevistas grabadasen estas comunidades tradicionales, con resultados concretos sobre siete de ellos, que han demostrado laausencia de políticas pública enaquellas comunidades y ausência de procesos específicos que conduzcana lacertificación de estosterritorios, muchos de loscualestienen una historia de ocupacióncimarrónde más de 200 años, conlapreservación de los rasgos importantes de la cultura afrodescendiente .

Plabras clave: Photoetnographia; Cimarrones; Juazeiro;Certifación de lós cimarrones.

\section{Introdução}

O projeto "Perfil fotoetnográfico das populações quilombolas do submédio São Francisco: identidades em movimento" percebe a importância de localizar e dar visibilidade as comunidades negras rurais quilombolas, identificadas através de imagens e de suas histórias, para, em seguida, traçar relações com as construções identitárias na região, mostrando a força e a pujança dessas culturas.

No projeto de pesquisa, temos trabalhado, desde 2011, com a perspectiva de que a herança cultural das populações afrodescendentes na região do submédio São Francisco, especialmente entre as cidades de Juazeiro (BA) e Petrolina (PE), pode ser percebida de várias formas, como em todo o Brasil: as expressões da linguagem, a composição fenotípica da população, a comida, a religião etc. No entanto, se percebe de forma incipiente a ligação identitária da população como um todo com os elementos que compõem a cultura afrodescendente, como forma de construção contínua das identidades de sujeitos que carregam essa origem e de atuação política cidadã. Dessa forma, a chamada cultura "afro" muitas vezes é folclorizada, apesar de fazer parte do dia a dia, e é percebida pelo senso comum como inerente apenas aos espaços fundadores da mesma, como os quilombos, sendo lembrada somente nas datas festivas, como o 13 de maio ou o 20 de novembro. Essa observação preliminar encerra uma contradição, pois a presença dos povos de origem africana nessa região é marcante.

A área que a pesquisa abrange corresponde ao submédio São Francisco, que engloba cidades nos estados da Bahia e Pernambuco, "estendendo-se de Remanso até a cidade de Paulo Afonso (BA), e incluindo as sub-bacias dos rios Pajeú, Tourão e Vargem, além da subbacia do rio Moxotó, último afluente da margem esquerda". (CODEVASF, 2009). Pelas 
cidades de Remanso, Sobradinho, Juazeiro, Curaça (1) e Paulo Afonso, na Bahia; Petrolina (2), Santa Maria da Boa Vista (3), Ouricuri, Belém do São Francisco, Floresta (2), Petrolândia (1) e Serra Talhada, em Pernambuco. Neste perímetro, segundo a Fundação Palmares (2013), existem pelo menos 9 comunidades certificadas e mais 17 sem certificação, representando, portanto, uma herança cultural inestimável para a região.

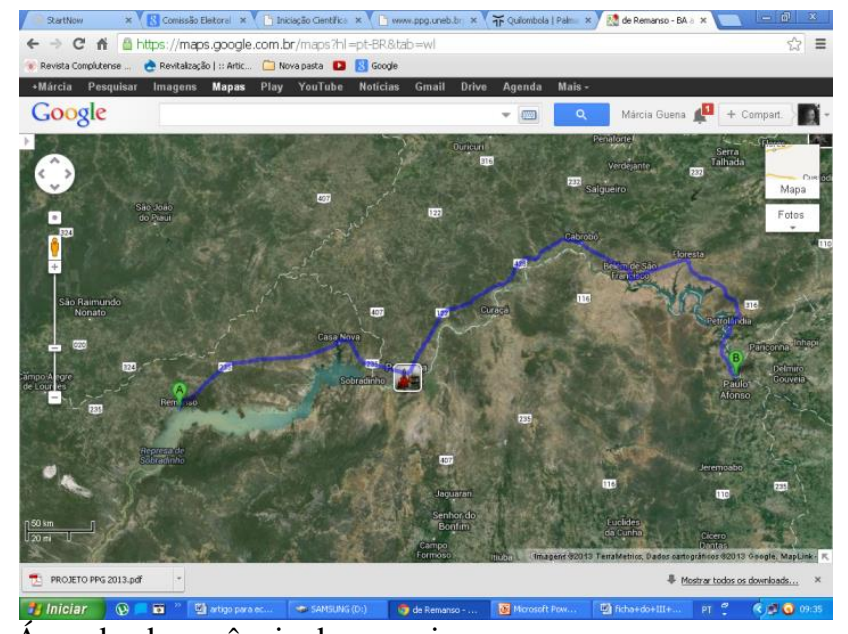

Área de abrangência da pesquisa

Muitas dessas comunidades têm sua cultura confinada em seus locais de origem. Inicialmente devido à condição de marginalidade das populações africanas ou de origem africana, saídas da escravidão, condição que se perpetuou ao longo do século XX; e segundo decorrente dos conflitos de terra, marcantes na região, nos quais essas populações continuam sendo empurradas de seus territórios.

Segundo a Fundação Cultural Palmares ${ }^{3}$ de acordo com dados de 2013, existem 2.197 comunidades reconhecidas oficialmente pelo Estado brasileiro como comunidades quilombolas; sendo que 2.040 comunidades foram certificadas pela Fundação Cultural Palmares, e 63\% delas estão no Nordeste. Porém, apenas 207 comunidades foram tituladas pelo INCRA, pois essa questão envolve as seculares lutas pela posse da terra no país e as comunidades devem enfrentar os difíceis trâmites exigidos pelo Estado para titulação da terra. Assim, existem 1.229 processos abertos para titulação.

Em Pernambuco, entre 2004 e 2013 ocorreram 108 certificações, e na Bahia, no mesmo período, 470. Em Juazeiro-BA, de acordo com a Fundação Palmares, não existe

\footnotetext{
${ }^{3}$ A Fundação Cultural Palmares foi criada em 1988 com a finalidade de promover, preservar e preservar a cultura afro-brasileiras. Uma das funções mais importantes da Palmares foi de fato a formalização das comunidades quilombolas e, segundo o site da instituição tem a função de " assessorá-las juridicamente e desenvolver projetos, programas e políticas públicas de acesso à cidadania”. FUNDAÇÃO PALMARES, 2012. Disponível em: http://www.palmares.gov.br/quem-e-quem/. Acessado em 10 de junho de 2012.
} 
nenhuma comunidade certificada; em Petrolina-PE, existem duas. No município vizinho a Juazeiro, Senhor do Bonfim-BA há 16 comunidades quilombolas certificadas, certamente em consequência de um trabalho de articulação já existente na região em torno do quilombo de Tijuassu, uma das primeiras comunidades certificadas naquela cidade, em $2005^{4}$.

Em Juazeiro existem 14 comunidades quilombolas, de acordo com levantamento do Ministério do Desenvolvimento, e nenhuma delas é certificada pela Fundação Cultural Palmares, órgão governamental responsável por esse trâmite burocrático. Algumas dessas comunidades estão em fase de etnogêse, recuperando a sua memória a fim de garantir, entre outras coisas, os direitos estabelecidos pelo estado. Outras, apesar de registradas nos órgãos do governo federal, não se reconhecem como quilombolas e nunca pensaram em qualquer vinculação dessa natureza.

Apesar disso, percebemos nas entrevistas realizadas com os moradores mais velhos, que a ocupação dessas áreas, em Juazeiro, data mais de 200 anos. Pessoas com mais de 80 anos relatam histórias de seus avós ou bisavós e suas formas de relação com a terra, que passava necessariamente pela ocupação de uma área muito maior do que a que vivem hoje e com acesso à água, diga-se, ao rio. Ou seja, há uma memória afrodescendente, ou negra, como passaremos a chamar a partir de agora, com relatos intensos da ocupação de origem africana na região, que devem ser considerados no estabelecimento de qualquer política pública.

Assim, diante desse panorama genérico, pretendemos nesse artigo, apresentar os primeiros resultados da pesquisa "Perfil fotoetnográfico das populações quilombolas do submédio São Francisco: identidades em movimento", articulando-o com a questão da certificação do território e posterior titulação da terra. O artigo será organizado da seguinte maneira: definições de quilombos, a metodologia utilizada e a discussão da certificação em cada uma das comunidades.

\section{Definições de quilombos}

Antes de prosseguir, é bastante importante definir o que são comunidades quilombolas, já que esse conceito sofreu mudanças, em função de inflexões políticas e ideológicas sofridas pela discussão. A definição que utilizamos de quilombos nesse artigo é bastante recente e foi emprestada da antropologia, como consequência de uma ampla discussão que teve à frente a Associação Brasileira de Antropologia (ABA), representantes de

\footnotetext{
${ }^{4}$ Ibidem.
} 
comunidades quilombolas e outros setores interessados na questão. Assim, em 1994, a Fundação Palmares promove em Brasília, entre os dias 25 e 27 de outubro, um seminário que culmina na elaboração de um significado para comunidades quilombolas, o qual foi absorvido pelo artigo 68 da Constituição Federal (O’DWYER, 2008).

Está expressa na terminologia "comunidades negras rurais quilombolas", territórios onde vivem as populações quilombolas de origem africana, conceito que incorpora as "terras de santo", "terras de preto", "mucambos" e quilombos (O’DWYER, 2002). Esses territórios não são fruto apenas da fuga de escravos no período escravocrata, com a consequente formação de um grupo de resistência ao sistema de então, eles representam formas diferenciadas de ocupação da terra, decorrentes de laços de consanguinidade, familiaridade, religiosidade entre outros:

Nesse sentido, é a passagem da condição de escravo para a de camponês livre que caracteriza esses agrupamentos, independentemente da estratégia utilizada pelo movimento de resistência. Assim, além da fuga com ocupação de terras livres - estratégia já amplamente difundida por materiais didáticos - o recebimento de terras como pagamento por serviços prestados ao Estado, como heranças, doações, compras ou mesmo permanência em terras privadas cujos proprietários não deixaram sucessores, também constituíram meios recorrentes de formação dessas comunidades (ANDRADE E TRECANNNI, 2000, p. 602, apud CHASIN).

Essa definição se encaixa perfeitamente nas áreas delimitadas pela pesquisa, pois muitas comunidades foram fruto de ocupações por populações de origem africana, sem que ali tivesse sido registrado algum episódio de luta. As famílias continuaram habitando os terrenos, perdendo, na maioria das vezes, espaço para latifundiários ou empresas agrícolas ${ }^{5}$. É o que temos visto nas visitas às comunidades quilombolas.

Em relação à ocupação do espaço, O’Dwyer define muito bem:

No que diz respeito à territorialidade desses grupos, a ocupação da terra não é feita em termos de lotes individuais, predominando seu uso comum. A utilização dessas áreas obedece a sazonalização das atividades, sejam agrícolas, extrativistas ou outras, caracterizando diferentes formas de uso e ocupação dos elementos essenciais ao ecossistema, que tomam por base laços de parentesco e vizinhança, assentados em relações de solidariedade e reciprocidade (O’DWYER, 2008).

Os órgãos governamentais utilizam a denominação "Comunidades remanescentes de quilombo", as quais definem como grupos étnico-raciais segundo critérios de autoatribuição,

\footnotetext{
${ }^{5}$ É importante salientar que há uma vasta bibliografia que trata dos quilombos e a questão da posse da terra que não será explorada nesse artigo.
} 
com trajetória histórica própria, dotados de relações territoriais específicas, com presunção de ancestralidade negra relacionada com a resistência à opressão histórica sofrida, de acordo com o estabelecido pelo Decreto 4.887/2003 (SEPIR, 2012). Sem negar a definição acima, a Fundação Palmares enfatiza que "Quilombolas são descendentes de africanos escravizados que mantêm tradições culturais, de subsistência e religiosas ao longo dos séculos" (FUNDAÇÃO PALMARES, 2013).

\section{Marcos legais para certificação de comunidades quilombolas}

O marco legal para as populações quilombolas começa a ser instituído a partir da constituição de 1988, que estabelece no Artigo 68 o seguinte: "Direito à propriedade das terras de comunidades remanescentes de quilombos. Aos remanescentes das comunidades dos quilombos que estejam ocupando suas terras é reconhecida a propriedade definitiva, devendo o Estado emitir-lhes os títulos respectivos."

Porém, o estabelecimento desse marco legal não foi suficiente para a realização da certificação e posterior titulação das comunidades quilombolas. Impedimentos de diversas ordens têm sido colocados para que a lei se cumpra e são muito maiores para a titulação das terras do que para a certificação, pois envolve o domínio da terra por grandes grupos ligados a agroindústria ou por latifundiários. Inicialmente o grande debate se deu em torno do reconhecimento das comunidades quilombolas e de como se daria esse processo, o que levou à exigência de elaboração do chamado Relatório antropológico de identificação territorial (SEPIR, 2012).

Inicialmente esse relatório poderia ser elaborado por um antropólogo indicado pela comunidade, porém agora o relatório deve ser feito por um profissional dessa área, indicado pelo INCRA, o que tem atrasado e dificultado os processos de titulação.

Com relação à certificação, o processo é mais simples e é feito pela Fundação Palmares, basta que a comunidade se autointitule como quilombola e siga os procedimentos exigidos pelo órgão.

Assim, o que queremos destacar é que, do ponto de vista do Estado há um marco legal, com vários impedimentos práticos, mas que está estabelecido. Abaixo segue uma relação de instrumentos legais que têm sido levados em conta no estabelecimento de direitos dessas populações, além do artigo 68:

Convenção 169 da OIT (Dec. 5051/2004) - Direito à autodeterminação de Povos e Comunidades Tradicionais; Decreto $\mathrm{n}^{\circ} 4.887$, de 20 de novembro de 2003 - Trata da 
regularização fundiária de terras de quilombos e define as responsabilidades dos órgãos governamentais; Decreto n ${ }^{\circ}$ 6040, de 7 de fevereiro de 2007 - Institui a Política Nacional de Desenvolvimento Sustentável dos Povos e Comunidades Tradicionais; Decreto ${ }^{\circ}$ 6.261, de 20 de novembro de 2007 - Dispõe sobre a gestão integrada para o desenvolvimento da Agenda Social Quilombola no âmbito do Programa Brasil Quilombola; Portaria Fundação Cultural Palmares $n^{\circ}$ 98, de 26 de novembro de 2007 - Institui o Cadastro Geral de Remanescentes das Comunidades dos Quilombos da Fundação Cultural Palmares, também autodenominadas Terras de Preto, Comunidades Negras, Mocambos, Quilombos, entre outras denominações congêneres; Instrução Normativa INCRA nº 57, de 20 de outubro de 2009 Regulamenta o procedimento para identificação, reconhecimento, delimitação, demarcação, desintrusão, titulação e registro das terras ocupadas por remanescentes das comunidades dos quilombos; Lei 10.639- 2003 sancionada pelo Presidente Lula, que torna obrigatório o ensino de História e da cultura Africana e Afro-brasileira, uma educação que respeita e garante uma educação multicultural. Sancionada desde 2003, está longe de ser aplicada efetivamente nas escolas brasileiras; A resolução de $\mathrm{N}^{\mathrm{o}}$ 8, de 20 de novembro de 2012, aborda as Diretrizes Nacionais para a Educação Escolar Quilombola na Educação Básica, e fundamenta-se na: Memória coletiva; Línguas reminiscentes; Práticas Culturais; Tecnologias e formas de produção do trabalho; Acervos e repertórios orais; Festejos, usos, tradições e demais elencos que formam o patrimônio cultural das comunidades quilombolas de todo o país; Territorialidade.

Em 2004, o governo federal lançou o Programa Brasil Quilombola, com o objetivo de “consolidar os marcos da política de Estado para as áreas quilombolas” (SEPIR, 2013), composto por 11 ministérios e gerido pela Secretaria de Políticas de Promoção da Igualdade Racial (Seppir). O programa trabalha com quatro eixos: acesso à terra; infraestrutura e qualidade de vida; inclusão produtiva e desenvolvimento local; e o último é "direitos e cidadania", cujo texto diz o seguinte:

Fomento de iniciativas de garantia de direitos promovidas por diferentes órgãos públicos e organizações da sociedade civil, estimulando a participação ativa dos representantes quilombolas nos espaços coletivos de controle e participação social, como os conselhos e fóruns locais e nacionais de políticas públicas, de modo a promover o acesso das comunidades ao conjunto das ações definidas pelo governo e seu envolvimento no monitoramento daquelas que são implementadas em cada município onde houver comunidades remanescentes de quilombos (SEPIR, 2013). 
Revista ComSertões

Assim, percebe-se que desde a constituição de 1988 o governo brasileiro vem construindo um marco legal que tem estabelecido políticas de ações afirmativas voltadas para a população negra, como consequência de uma forte pressão de diversas vertentes dos movimentos negros. Porém, muitas comunidades quilombolas desconhecem essas leis e, principalmente, a forma de acessá-las. Essa é uma realidade vivida por uma parte das comunidades visitadas pelo nosso grupo de pesquisa. Ser quilombola, reconhecer o seu passado e sua memória atrelada à ocupação das terras por descendentes de africanos não é um processo natural em uma sociedade que não conhece a sua história e seus direitos e onde a presença do Estado é mínima ou nula. Assim, ser quilombola torna-se também um privilégio para aqueles que conseguem aceder a esse aparato legal e reconstruir uma memória nos marcos exigidos pela Lei.

Deve-se ressaltar que a maioria dos grupos visitados é formada por comunidades em fase de auto-reconhecimento ou apenas mencionadas nos órgãos oficiais como quilombolas, sem o estabelecimento de qualquer marco identitário e legal concretos. Esse aspecto aponta para uma forte ausência do Estado em áreas reconhecidas por ele mesmo como quilombola, mas sem qualquer tipo de política que permita a essas populações, há muito alijadas de direitos básicos, ter acesso a eles, ou pelo menos aceder ao conhecimento de que possuem direitos (SANTOS E SANTOS, 2013).

\section{Metodologia}

Para a construção do banco de dados temos utilizado uma metodologia central que é a fotoetnografia, porém trabalhamos com várias outras metodologias da antropologia e da comunicação: o caderno de campo como ferramenta da construção etnográfica, e a gravação de entrevistas semi-abertas em áudio e vídeo com o objetivo de registrar a memória dos moradores mais velhos da comunidade. Esses métodos são capazes de abordar vários aspectos do ser quilombola, que passa pela territorialidade e pela memória social do grupo, elementos indispensáveis para os processos de certificação.

A linguagem fotográfica com que trabalhamos pensa a comunicação visual na sua dimensão pós-estruturalista, liberta do positivismo dos primeiros trabalhos, enquanto possibilidade em si, possibilidade da construção de outro ponto de vista, tendo a imagem como representação dos vários discursos presentes no processo de organização da memória de uma comunidade, que busca responder a um marco legal estabelecido pelo estado e pelas próprias demandas do grupo, com suas diversas interações com organizações externas. 
O trabalho fotoetnográfico, além dessa dimensão intrínseca da representação da imagem, também carrega consigo a representação do olhar do fotógrafo, o qual pode ser mais ou menos estrangeiro, mas sempre estrangeiro. Tudo irá depender do grau de interação com a comunidade. Assim, tentamos construir uma pesquisa participante com a finalidade de reduzir as distâncias entre os dois discursos. Para isso, uma das principais estratégias é a construção de oficinas de fotografia, nas quais os moradores representam aspectos que lhe interessam de seu território e do grupo. Tudo isso pode ser dito em uma frase de Berger (1999): "Só vemos aquilo que olhamos. Olhar é um ato de escolha”. E esta escolha pode ficar a critério do grupo e não do fotógrafo, provocando um sentido mais profundo na construção do perfil fotoetnográfico.

Segundo Ribeiro (2005) a antropologia visual ou comunicação visual está centrada em três objetivos principais: a utilização das tecnologias de som e da imagem na realização do trabalho de campo (...); a construção de discurso ou narrativas visuais (o uso das tecnologias na apresentação dos resultados da pesquisa - nos museus, no ensino, na comunicação com o grande público - na estruturação da narrativa fílmica, ou de multimídia e hipermídia, e em sua realização) (...); a análise dos produtos visuais (RIBEIRO, 2005). Assim, pensando nos marcos estabelecidos por Ribeiro, estamos trabalhando com dois dos objetivos listados, pois utilizamos as tecnologias do som e da imagem para a construção de narrativas baseadas na memória e nas imagens dos sujeitos e de seus territórios.

Para pensar a fotoetnografia um dos principais autores trabalhados por nós é Luiz Eduardo Achutti. Para este autor, esse termo encerra a ideia de ter a fotografia como principal linguagem narrativa nas pesquisas etnográficas, constituindo-se como principal elemento da narrativa, já que a linguagem textual sempre teve destaque no universo da antropologia e a fotografia entrava apenas como ferramenta complementar do discurso (ACHUTTI, 2004). No campo da comunicação, a fotografia como narrativa já é uma constante em vários trabalhos, relacionando-se com outras metodologias. Dialogando com a antropologia visual, Achutti ressalta o "potencial narrativo das imagens fotográficas utilizadas sob a forma de narrativas visuais" (BIAZUS, 2006). Achutti propõe que se trabalhe com sequências organizadas de imagens que permitam a construção de uma história. As fotografias "devem ser objeto de construções sob forma de sequências e de associações de imagens, tendo por objetivo treinar o leitor a praticar outras associações para nelas encontrar uma significação" (ACHUTTI, p. 117, apud BIAZUS, 2006, p. 3). Como método ele sugere o planejamento prévio das imagens a serem realizadas e que sejam apresentadas sem textos explicativos, legendas ou outros comentários, o que pode ser feito previamente no texto. (SANTOS, 2014). 
Reconhecendo na fotografia o seu aspecto híbrido, enquanto documento e expressão, como conceitua Rouillé (2010), associada à sua possibilidade etnográfica, ou fotoetnográfica, temos realizado perfis das comunidades visitadas, dos seus territórios e seus sujeitos, capazes de integrar possíveis processos de certificação. Nas comunidades até agora visitadas, não existe qualquer tipo de sistematização da memória local, o que representa mais um elemento na construção dessa dimensão imagética dos grupos em questão.

\section{Perfil fotoetnográfico e contribuições para uma possível certificação ${ }^{6}$}

A pesquisa realizou o perfil fotoetnográfico de oito comunidades quilombolas na cidade de Juazeiro-BA: Barrinha da Conceição, Rodeadouro, Alagadiço, Pau Preto, Barrinha do Cambão, Junco, Quipá e Curral Novo. Em apenas duas delas, Barrinha do Cambão e Barrinha da Conceição, a comunidade já havia se mobilizado no sentido de buscar o reconhecimento como comunidade quilombola. Nas demais, apesar de constarem da lista do Ministério do Desenvolvimento, nunca houve uma mobilização efetiva para a conquista de um marco legal. Porém, nas entrevistas realizadas com os moradores mais velhos, a memória de uma herança afrodescendente está presente, seja na história de constituição do território ou nas manifestações culturais. Vamos a seguir traçar um ligeiro perfil de cada comunidade visitada.

$\mathrm{Na}$ estrada que sai de Juazeiro rumo ao Rodeador, um lugarejo que abriga uma ilha paradisíaca de mesmo nome e bastante turística, localizada a 13 quilômetros do centro de Juazeiro, há uma pequena estrada de barro, antes do Rodeador que leva, por 2 quilômetros a Barrinha da Conceição. Um lugarejo, às margens do Rio São Francisco, onde vivem cerca de 10 famílias, aproximadamente 60 pessoas, herdeiras de descendentes de africanos recémsaídos do sistema escravocrata, que fugiram da Guerra de Canudos (1896-1897). O nome do local é uma homenagem a Nossa Senhora da Conceição, cuja festa acontece na comunidade no dia 29 de novembro a 08 de dezembro. Na comunidade não há escola, posto de saúde ou água potável, apesar de ser uma das mais ativas de Juazeiro e que tem lutado por seus direitos. A formação escolar é feita em comunidades vizinhas, a despeito da precariedade do transporte.

O perfil fotoetnográfico realizado pela pesquisa em Barrinha da Conceição traçou o tamanho do território, o que pode colaborar no sentido da demarcação da área quilombola, o

\footnotetext{
${ }^{6}$ Parte das informações desse tópico foram extraídas do blog da pesquisa "Perfil Fotoetonográfico das Populações Quilombolas do submédio São Francisco: identidades em movimento" www.quilombosesertoes.blogspot.com
} 


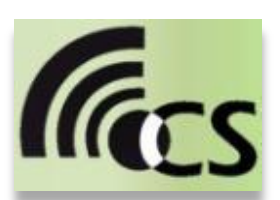

Revista ComSertões

perfil da família mais antiga e a festa da padroeira local. Nas imagens abaixo estão Dona Roberta Maria dos Santos Oliveira, quem preserva a memória local; logo em seguida uma imagem do rio São Francisco e da festa da padroeira.
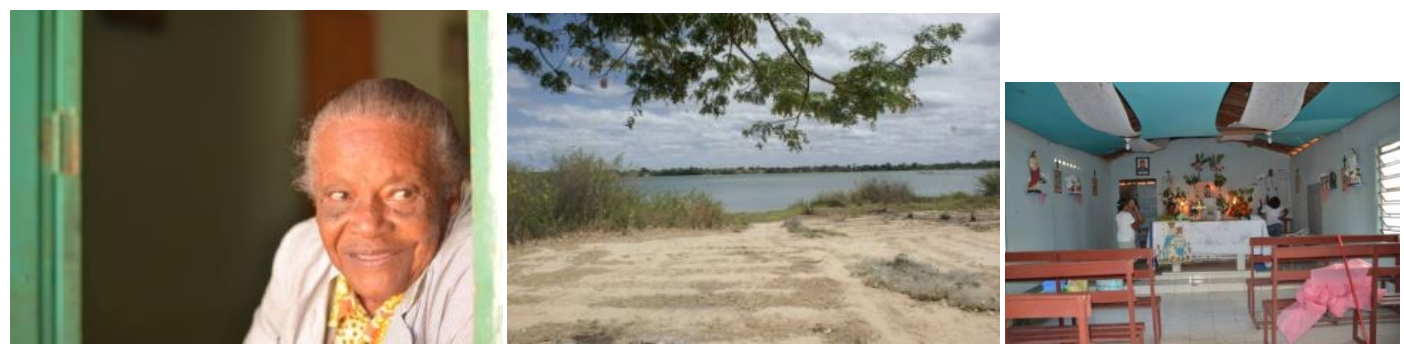

A Comunidade Quilombola Alagadiço fica a cerca de 20 quilômetros do centro de Juazeiro, após o Rodeador. Com cerca de 30 famílias, a fonte de renda principal era a agricultura familiar e a pecuária, no entanto muitas famílias venderam suas terras, localizadas às margens do Rio São Francisco. As instalações da escola estão lá, mas não há atividade. Não existe um posto de saúde e o transporte é precário. Em momentos diferentes a comunidade se mobilizou pela garantia de seus direitos, inclusive a posse da terra, porém a discussão quilombola nunca foi pauta efetiva, apesar do grande interesse demonstrado. Hoje a comunidade tenta se mobilizar, através da universidade, para garantir esse direito, já que há um grupo atuante, liderado por Dona Alvina dos Antos, Dona Vinô, na foto abaixo, que se considera quilombola

O perfil fotoetnográfico estabeleceu os limites do território, cercado por propriedades, fotografou as famílias mais velhas e foi possível realizar uma oficina de fotografia, onde os participantes registraram aspectos de interesse do grupo. Na sequencia de imagens estão Dona Alvina dos Santos, conhecida como Vinô, uma casa da localidade e uma propriedade que cerca o local.

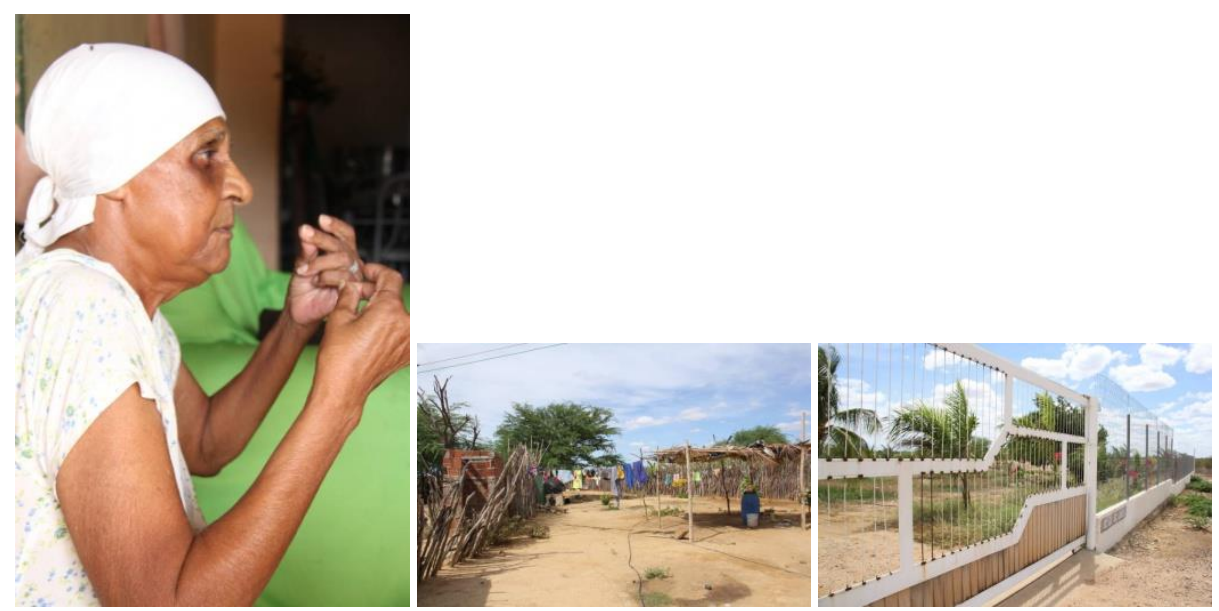

Na sequência estão Dona Vinô, uma imagem da comunidade e a propriedade que a cerca. 
Pau Preto é uma comunidade localizada acerca de 15 quilômetros do centro da cidade de Juazeiro, após o Junco, na área conhecida como Salitre, onde moram cerca de 60 famílias de origem quilombola, quase todos parentes. A escola no local também está desativada o que gera o deslocamento das crianças para outras comunidades e não há posto de saúde. Os jovens tem saído do local em busca de trabalho e de melhores condições de vida. A memória quilombola é viva e presente, porém não tem se convertido em ações concretas. Na sequencia de imagens, seu Antonio Gomes, um dos moradores mais velhos que nos acompanhou em uma visita pela comunidade, o leito seco do Rio Salitre e uma vista panorâmica da comunidade. Aí também foi possível delimitar o tamanho da comunidade, antes banhada pelo rio Salitre, com uma história de trabalho agrícola comunitário e de folguedos ao redor do rio.

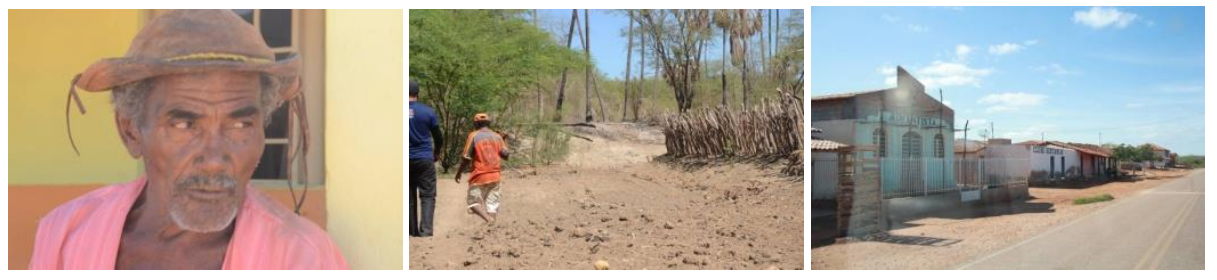

Barrinha do Cambão é uma comunidade ribeirinha, localizada a aproximadamente cinco quilômetros do centro da cidade de Juazeiro. O povoado conta com cerca de 350 moradores, tem nas atividades pesqueira e agrícola as principais formas de sobrevivência. A comunidade conta com uma creche que atende crianças até seis anos, depois dessa idade os pequenos vão estudar no Projeto Mandacaru, a três quilômetros de distância. A discussão quilombola é presente na comunidade e, no início dos anos 90, iniciaram um intenso debate que gerou um plebiscito e parte dos moradores foi contra a busca de identificação quilombola e posterior certificação do território. Hoje a discussão está sendo retomada, com mais adesões. O território foi cindido ao meio por um dos projetos de irrigação da Codevasf e entrecortada por propriedades privadas. Assim a área original ficou bastante reduzida e uma outra parte importante foi vendida pelos herdeiros quilombolas. O perfil fotoetnográfico entrevistou Pedro e Ana Maria, que trabalharam para a certificação e identificou a área ocupada pela comunidade. Nas fotos abaixo estão o canal de irrigação do Projeto Mandacaru, Pedro e Ana Maria, moradores responsáveis pelo plebiscito para o reconhecimento como comunidade quilombola e uma visão de uma área privada dentro do território antes ocupado pelos quilombolas. 


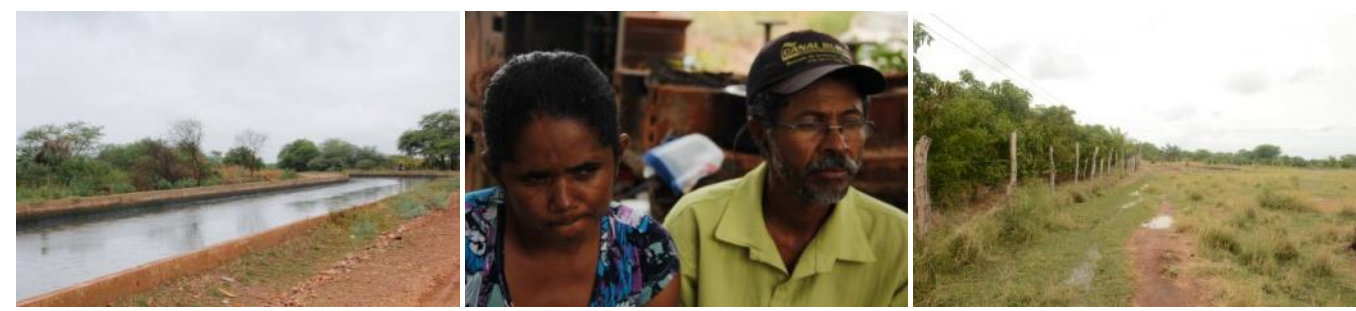

Curral Novo, localizada a cerca de 20 quilômetros do centro de Juazeiro, consta na lista da Fundação Palmares como comunidade quilombola, assim como muitas outras localizadas às margens do Rio São Francisco. Uma comunidade predominantemente negra, que inicialmente vivia às margens do riacho que banha a localidade, com o mesmo nome do Rio Salitre. A enchente de 1960 e a constante perda de terras os deslocou para onde estão hoje. Uma população predominantemente negra, com uma história de aproximadamente 150 anos de ocupação. A escola municipal local atende as primeiras séries do ensino fundamental de várias outras comunidades vizinhas, preservando valores ligados à memória quilombola. $\mathrm{O}$ nome Escola Municipal Miguel Ângelo de Souza é uma homenagem ao seu fundador, um homem negro que deixou muitos parentes na localidade. Essa é uma das duas comunidades visitadas em que a escola tem procurado resgatar a memória local, trabalhando com alguns elementos das diretrizes para educação quilombola.

O perfil fotoetnográfico delimitou o espaço da comunidade, constatando que proprietários particulares compraram as principais áreas que davam acesso ao rio e passaram a constituir projetos de agronegócio, empregando a população quilombola, que abandonou o cultivo de subsistência. Abaixo uma vista aérea da comunidade e a escola.
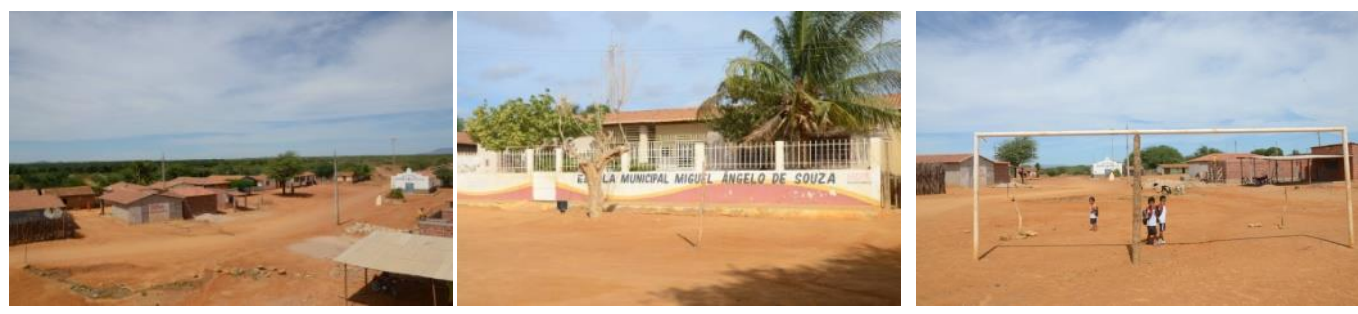

O Quipá está a 20 quilômetros do centro de Juazeiro. Nascida às margens do rio São Francisco, recebe o mesmo nome de um cactáceo muito comum no local. Embora tenha sido classificada pelo Ministério do Desenvolvimento como quilombola, não se reconhece como tal, restando apenas uma memória quilombola vaga que pôde ser apurada em entrevista com os moradores mais velhos. A comunidade foi deslocada do seu lugar de origem, para uma área muito menor, após a instalação de uma companhia de frutas, ainda em funcionamento, que 


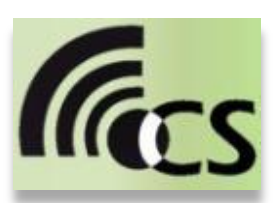

Revista ComSertões

alegou a propriedade da terra. Porém alguns problemas se repetem: falta de saneamento básico e coleta de lixo. Cerca de 300 pessoas vivem na localidade, distribuídas entre aproximadamente 60 ou 70 famílias. A pesca constitui-se na principal fonte de renda dos moradores da comunidade. A escola municipal local, assim como em Curral Novo, tem procurado valorizar elementos da memória quilombola e abriu espaço para uma intervenção mais prolongada do projeto de pesquisa, com a realização de debates e oficinas.

Através do perfil fotoetnográfico podemos delimitar o território e registrar os moradores mais velhos que detêm a memória quilombola. Abaixo uma vista panorâmica da chegada à comunidade; seu José Domingos de Brito, um dos moradores mais velhos; e um dos acessos livre ao rio.

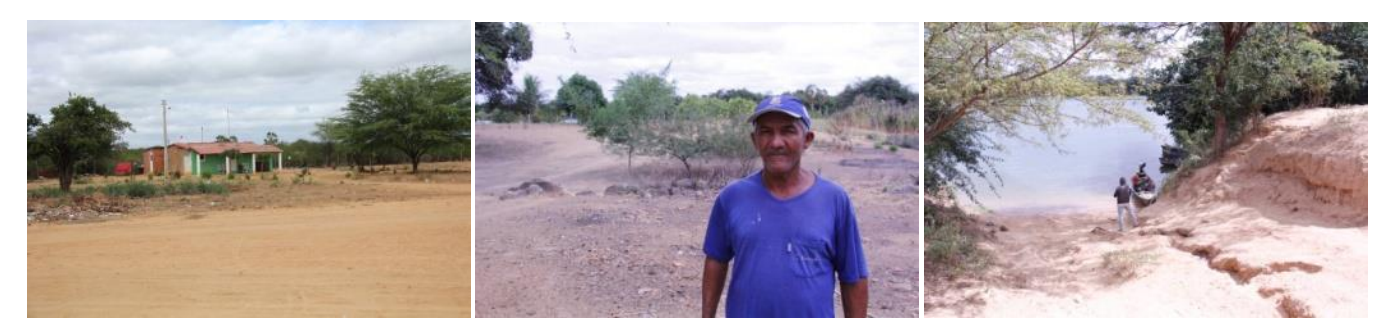

Na comunidade do Junco, a cerca de 90 quilômetros do centro de Juazeiro, cerca de 40 famílias constituem a comunidade, quase todos parentes, porém não há qualquer menção a uma memória quilombola. No passado existia engenho de cana no local e resta uma história relacionada a um muro de pedra construído por "escravos". A escola municipal está em funcionamento e tenta trabalhar com alguns elementos da cultura negra, mas desvinculado de uma memória quilombola. O perfil estabeleceu a extensão do território e registrou a história de um dos moradores mais velhos, seu Antônio. Abaixo a sequencia mostra seu Antonio no muro de pedra construído pelos africanos escravizados, como contou ele; o rio salitre antes da seca e uma vista panorâmica da comunidade.

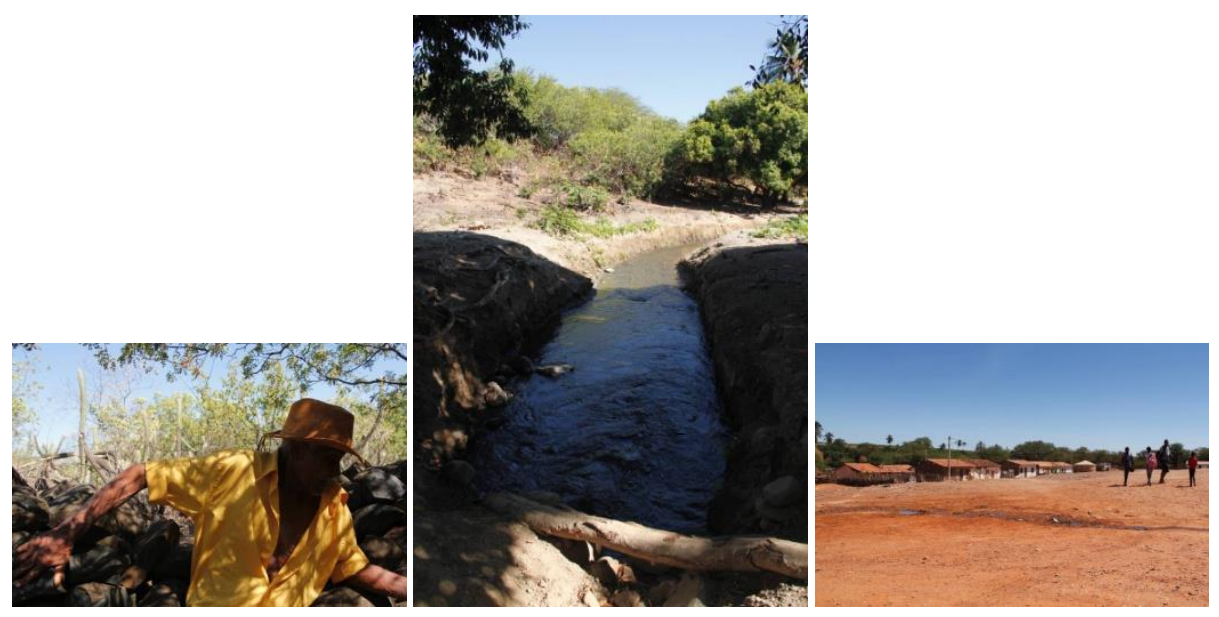




\section{Considerações finais}

A pesquisa "Perfil Fotoetonográfico das Populações Quilombolas do submédio São Francisco: identidades em movimento" traçou o perfil de oito comunidades apontadas como quilombolas pelo Ministério do Desenvolvimento, em Juazeiro e nenhuma delas com certificação emitida pela Fundação Palmares, órgão do governo responsável por esse processo.

Através da construção de perfis fotoetnográficos, ancorados em outras linguagens da comunicação, como vídeos e entrevistas, conseguimos realizar a construção de um banco de dados inicial contendo a extensão desses territórios e suas principais lideranças. Ainda que tenhamos tentando evitar o olhar estrangeiro através da promoção de oficinas de fotografia para os moradores, na maioria das visitas as imagens foram realizadas pelo grupo, o que ainda aponta para uma representação centralizada em nosso ponto de vista. Só conseguimos realizar as oficinas em duas comunidades.

Os perfis fotoetnográficos apontam para áreas desprovidas de aparelhos públicos, como escolas, postos de saúde, asfaltamento ou saneamento básico, indicando a ausência do poder público, apesar do marco legal já ter sido constituído para as comunidades quilombolas no Brasil. As cercas de propriedades privadas nessas áreas quilombolas indicam também a perda histórica do território e o afastamento do rio, como principal fonte articuladora da comunidade, no que diz respeito à subsistência e a realização de atividades culturais aglutinadoras.

Os moradores mais velhos estão representados nas imagens coletadas, geralmente em suas casas. Em geral receberam bem os entrevistadores e não se opuseram à construção das imagens. Como pode ser visto ao longo deste artigo, são pessoas negras, que contam a história da ocupação do território. Todo o material utilizado na construção desse banco de dados está sendo sistematizado e será entregue a cada comunidade, com o objetivo de contribuir nos processos de certificação daquelas que assim o desejarem. A entrega será feita ao morador mais antigo e ao líder comunitário. Em algumas comunidades percebemos que esse material contribuirá na construção do processo de certificação. Em outras poderá apenas constituir a memória local, o que também é importante dentro do processo de construção identitária.

\section{Referêcias bibliográficas}


Revista ComSertões

AMORIN, Itamar Gomes; GERMANI, Guiomar Inez. Quilombos da Bahia. Presença incontestável.Anais do X Encontro de Geógrafos da América Latina - 20 a 26 de março de 2005 - Universidade de São Paulo. Disponível em:

http://observatoriogeograficoamericalatina.org.mx/egal10/Geografiasocioeconomica/Geografi adelapoblacion/03.pdf. Acessado em 2 de abril de 2011.

ARRUTI, José Maurício. Quilombos. In: PINHO, Osmundo; SANSONE, Lívio. Raça. Novas Perspectivas antropológicas. Salvador: Associação Brasileira de Antropologia; Edufba, 2008.

BIAZUS, Paula de Oliveira. Resenha do livro. Horizontes Antropológicos, Porto Alegre, ano 12, n. 25, p. 301-306, jan./jun. 2006.

BONI, Paulo César; MORESCHI, Bruna Maria. Fotoetnografia: a importância da fotografia para 0 resgate etnográfico. Disponível em: <http://www.doc.ubi.pt/03/artigo_paulo_cesar_boni.pdf> Acessado em 15 de março de 2011.

BERGER, Jonh. Modos de Ver. Rio de Janeiro, Rocco, 1999.

CAMPOS, Carla Siqueira. Rio São Francisco: O Rio da Injustiça Ambiental. Encontro Nacional da ANPPAS, 4., 2008, Brasília. Koinonia. Disponível em: http://www.koinonia.org.br/tpdigital/detalhes.asp?cod_artigo=214\&cod_boletim=12\&tipo=A rtigos. Acessado em: 10 set. 2011.

CEAFRO. Selo Unicef Município Aprovado. Cultura e identidade afro-brasileira e indígena. Brasília, Unicef, 2008.

CHASIN, Ana Carolina da Matta. 20 Anos de Regularização Fundiária de Territórios Quilombolas: um balanço da implementação do direito à terra estabelecido pela Constituição Federal de 1988. Revista Política Hoje, Vol. 158 18, n. 2, 2009, p.160.

CODEVASF. PLANVASF. Plano Diretor para o Desenvolvimento do Vale do São Francisco. Disponível em: http://www.codevasf.gov.br/principal/publicacoes/publicacoesatuais/planvasf. Acessado em 01 de abril de 2011.

CAMPOS, Carla Siqueira. Conjuntura quilombola no sertão de Pernambuco. Disponível em:

http://www.koinonia.org.br/tpdigital/detalhes.asp?cod_artigo=214\&cod_boletim=12\&tipo=A rtigos. Acessado em: 16 out. 2011

FUNDAÇÃO PALMARES. Disponível em: http://www.palmares.gov.br.

GOMES, Nilma Lino. Educação e relações raciais: refletindo sobre algumas estratégias de atuação, in MUNANGA, Kabengele(Org.), Superando o racismo na escola. SECAD/ $\mathrm{MEC} / \mathrm{BID} / \mathrm{UNESCO}, 2005$.

GEOGRAFAR. Disponível em: http://www.geografar.ufba.br/estudo\%20msf.html. Acessado em 11 de março de 2011. 
Revista ComSertões

MATTOS, Wilson. Negros contra a ordem. Astúcias, resistências e liberdades possíveis (Salvador-Ba 1850-1888). Salvador, Eduneb,Edufba, 2008.

O’Dwyer, Eliane Cantarino. Terras de Quilombo no Brasil: direitos territoriais em construção.

PINHO, Osmundo; SANSONE, Lívio. Raça. Novas Perspectivas antropológicas. Salvador: Associação Brasileira de Antropologia; Edufba, 2008.

REIS, João José; GOMES, Flávio dos Santos. Liberdade por um fio: história dos quilombos no Brasil. São Paulo: Companhia das Letras, 1996.

QUILOMBOS E SERTÕES. Disponível em: www.quilombosesertoes.blogspot.com.

ROUILLÉ, André. A fotografia: entre o documento e arte contemporânea. São Paulo, Editora SENAC, 2010.

SANTOS, Lucimar Felisberto. Os bastidores da lei: estratégias escravas e o Fundo de Emancipação. Revista História. Disponível em: http://www.revistahistoria.ufba.br/2009_2/a02.pdf. Acessado em: 16 out. 2011.

SANTOS, Márcia e SANTOS, Ceres. Escolas em comunidades negras rurais quilombolas de Juazeiro: uma aproximação dentro da educação contextualizada. Artigo submetido ao III WORKSHOP NACIONAL EM EDUCAÇÃO CONTEXTUALIZADA PARA A CONVIVÊNCIA COM O SEMIÁRIDO BRASILEIRO e II COLÓQUIO DE PÓSGRADUAÇÃO DO VALE DO SÃO FRANCISCO, setembro de 2013. Territórios e Interculturalidade na Perspectiva da Educação Contextualizada (Artigo aceito).

SILVA, Valdélio Santos. Rio das Rãs e Mangal Feitiçaria e poder em territórios quilombolas do Médio São Francisco. Tese de doutorado apresentada ao Programa Multidisciplinar de Estudos Étnicos e Africanos da Universidade Federal da Bahia (UFBA). Salvador, 2010.

SECRETARIA DE PROMOÇÃO DA IGUALDADE RACIAL - SEPIR. Programa Brasil Quilombola. Diagnóstico de Ações Realizadas. Julho de 2012, p. 12. Disponível em: http://www.seppir.gov.br/destaques/diagnostico-pbq-agosto. Acessado em: 04 de agosto de 2013. 